Revista Brasil. Bot., V.32, n.2, p.249-252, abr.-jun. 2009

\title{
Uma nova espécie de Croton sect. Geiseleria (Euphorbiaceae) da Amazônia Oriental brasileira
}

\author{
RICARDO DE S. SECCO ${ }^{1}$
}

(recebido: 23 de agosto de 2007; aceito: 9 de fevereiro de 2009)

\begin{abstract}
A new species of Croton sect. Geiseleria (Euphorbiaceae) from Eastern Amazonian Brazil). A new species of Euphorbiaceae from Amazonian Brazil, Croton strobiliformis Secco, is described. This species is superficially similar to C. hirtus L'Heritier, but differs in having branches sparsely pubescent, glabrescent, leaves with dense indument of stellateporrects trichomes on both sides, slightly rough abaxially, with veins conspicuously more evident abaxially than adaxially, stipules 2, aciculate, inflorescence strobiliform, with many pistillate flowers grouped at the base, petals of staminate flower internally with dense indument of villose trichomes, stamens with villose trichomes at the base, and fruit with indument velutinous. The systematic position of $C$. strobiliformis in relation to the sections of Croton is discussed.
\end{abstract}

Key words - Croton, Euphorbiaceae of Amazonia, new species

RESUMO - (Uma nova espécie de Croton sect. Geiseleria (Euphorbiaceae) da Amazônia Oriental brasileira). Uma nova espécie de Euphorbiaceae da Amazônia brasileira, Croton strobiliformis Secco, é descrita. Essa espécie é superficialmente semelhante a $C$. hirtus L'Heritier, mas pode ser distinguida pelos seguintes caracteres: ramos esparsamente pubescentes, glabrescentes, folhas com denso indumento de tricomas estrelado-porrectos em ambas as faces, levemente áspera na abaxial, com nervuras acentuadamente mais evidentes que na face adaxial, estípulas 2, aciculadas, inflorescência em racemo estrobiliforme, flores pistiladas várias, agrupadas na base da inflorescência, pétalas das flores estaminadas com denso indumento de tricomas vilosos internamente, estames com tricomas vilosos na base e frutos com indumento denso-velutino. A posição sistemática de $C$. strobiliformis em relação às seções de Croton é discutida.

Palavras-chave - Croton, Euphorbiaceae da Amazônia, espécie nova

\section{Introdução}

Croton L. é um dos maiores gêneros das Euphorbiaceae, com cerca de 1.200 espécies, a maioria distribuída nas Antilhas e América do Sul, e algumas na América do Norte (Webster 1994; Govaerts et al. 2000). Suas espécies são árvores, arbustos, ervas e lianas, geralmente monóicas, algumas vezes dióicas, com tricomas de formas variadas (estrelados, escamiformes etc.). Em geral as inflorescências apresentam as flores pistiladas na base e as estaminadas no ápice, os estames dobrados no botão floral e as pétalas das flores pistiladas reduzidas ou ausentes. Desde o tratamento de Mueller (1873), na Flora Brasiliensis, as espécies brasileiras não foram revisadas e diversos táxons novos vêm sendo propostos, o que tornou confusa a taxonomia de Croton. Alguns tratamentos recentes sobre as espécies da América do Sul, como os de Cordeiro (1992), Secco (1992), Murillo (1999) e Webster et al. (1999) ainda são insuficientes para que se possa avaliar precisamente os limites específicos em Croton. Nos herbários da Amazônia brasileira (IAN, INPA e MG)

1. Museu Paraense Emilio Goeldi, Coordenação de Botânica, Av. Magalhães Barata 376, 66040-170 Belém, PA. rsecco@museugoeldi.br há um grande número de espécimes mal identificados ou indeterminados, o que faz com que o presente estado de conhecimento de Croton na região ainda seja precário.

Como parte de uma revisão do gênero na Amazônia Brasileira, encontrou-se uma coleção procedente do estado do Pará (Rio Tocantins, Município de Tucuruí), cujas características morfológicas a enquadram em uma nova espécie, que a seguir é descrita, comentada e ilustrada.

\section{Resultados e discussão}

Croton strobiliformis Secco, sp. nov. Tipo: BRASIL. PARÁ: Tucuruí, margem direita do Rio Tocantins, BR-263, km 16, campina de solo arenoso, 30-I-1980, P. Lisboa, U. Maciel, M.G. Silva e R.P. Bahia 1286 (holótipo MG; isótipo NY).

Figura 1

Frutex monoicus ramis pubescentibus, glabrescentibusque. Folia palmatinervia ad basin glandulis stipitatis binis instructa, superficie abaxiale dense pubescent, nervi superficie abaxiale quam adaxiale manifestioribus, stipulis 2, aciculatis, margine conspicue aculeate serrulato. Inflorescentia in racemis strobiliformibus disposita. Flores staminati in alabastris, 


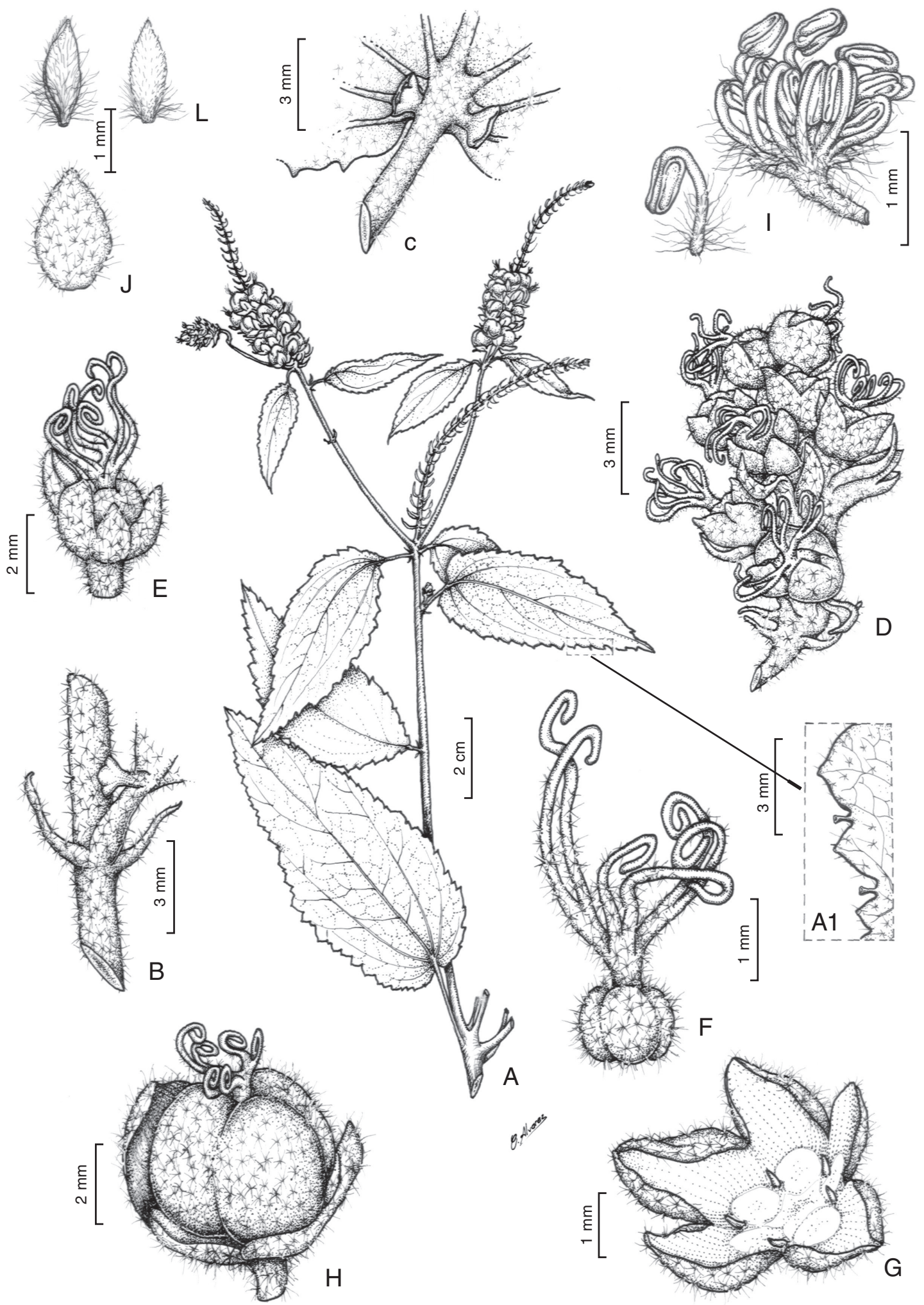

Figura 1. Croton strobiliformis Secco. A. Ramo. A1. Detalhe da margem da folha com glândulas estipitadas. B. Par de estípulas e glândula. C. Par de glândulas da base da folha. D. Detalhe da base da inflorescência. E. Flor pistilada. F. Ovário. G. Cálice da flor pistilada; pétalas obsoletas, na base. H. Fruto. I. Androceu (de um botão em pré-antese) e estame separado, em detalhe. J. Sépala, vista externa (de um botão estaminado em pré-antese). L. Pétalas, vistas externa e interna (de um botão estaminado em pré-antese). (Lisboa et al. 1286). 
staminibus 11. Flores pistillati varii ad basin infloresentiae congesti, petalis 5 reductis vel obsoletis, stylis bifidis. Fructus indumento dense velutino obtectus.

Arbusto $1 \mathrm{~m}$ alt. Ramos pubescentes, glabrescentes. Folhas 3-9 cm compr., 2,5-5 cm larg., oval-lanceoladas, palmatinérveas, cartáceas, denso indumento de tricomas estrelado-porrectos, levemente áspero ao tato na face abaxial, indumento de tricomas estrelado-porrecto na face adaxial, bastante áspero ao tato, margem denteadoserrilhada, com glândulas estipitadas nos espaços entre os "dentes", base cordada, trinervada, com um par de glândulas cupuliformes, estipitadas, na face abaxial, no ponto de união com o pecíolo, ápice acuminado, nervuras mais nítidas na face abaxial (à vista desarmada); pecíolo 0,5-7 cm compr., densamente piloso a pubescente (nas folhas mais maduras), tricomas estrelados; estípulas basais 2, aciculadas, 3,5-4,5 mm compr. Inflorescências em racemo estrobiliforme, congestas, 3-5 cm compr., bissexuadas, aparentemente protogínicas, com flores pistiladas densamente agrupadas na base, as estaminadas em maior quantidade no ápice, infrutescências $5,5-7 \mathrm{~cm}$ compr. Flores estaminadas em fase de botão, bastante jovens, com bractéola linear-lanceolada, ungüiculada, côncava, pilosa, inserida na base do pedicelo, 2-2,5 mm, observadas apenas duas em pré-antese na inflorescência; pedicelo 1,2 $\mathrm{mm}$ compr., piloso, tricomas estreladoporrectos; sépalas 5, livres, ovais, côncavas, 1,5-1,8 mm compr., pilosas externamente, tricomas estreladoporrectos, glabras internamente; pétalas 5, livres, elípticas, côncavas, $c a$. 1,5 mm compr., pubescentes externamente, com tricomas vilosos, curtos, prateados, denso-pilosas internamente, com denso indumento de tricomas vilosos, longos, dourados; estames 11, dobrados no botão floral, 1,8-2,5 mm compr., com um tufo de tricomas vilosos na base. Flores pistiladas com bractéola linear-lanceolada, ungüiculada, côncava, pilosa, inserida na base do pedicelo, $3 \mathrm{~mm}$ compr.; pedicelo $1 \mathrm{~mm}$ compr., piloso; cálice 5-lobado, lobos ovais, desiguais, côncavos, 1,5-2,5 mm compr., pilosos externamente, glabros internamente, pétalas obsoletas, extremamente reduzidas; ovário 1-1,2 mm diâm., globoso, denso-piloso, indumento de tricomas estrelado-porrectos; estiletes 3, bífidos, pubescentes, 3-3,5 mm compr., filiformes, concrescidos $0,5 \mathrm{~mm}$ na base, ultrapassando discretamente o cálice em comprimento. Fruto 5,5-6 mm diâm., subgloboso, mericarpos bem acentuados, denso-indumento de tricomas estrelados, velutino ao tato, sépalas e estiletes persistentes.

Esta espécie foi coletada, à época, em uma área muito pouco explorada da Amazônia, a quando da construção da Usina Hidrelétrica de Tucuruí, constituindo-se até o presente na única amostra conhecida nos herbários consultados (IAN, MG, NY, INPA).

Croton strobiliformis provavelmente faça parte de um complexo de espécies endêmicas do Brasil, da seção Geiseleria (Klotzsch) Baill. Entretanto, por apresentar as folhas com glândulas estipitadas na base, margem denteada, cálice da flor pistilada com os lobos desiguais, estiletes bífidos, cálice da flor estaminada pubescente externamente e 11 estames, Croton strobiliformis parece estar superficialmente relacionada com $C$. hirtus L'Heritier, de ampla distribuição neotropical, considerando-se as espécies conhecidas encontradas na Amazônia brasileira; mas pode ser distinguida pelos seguintes caracteres: ramos esparso-pubescents, glabrescentes, folhas com denso indumento de tricomas estrelado-porrectos em ambas as faces, levemente áspera na abaxial, com nervuras acentuadamente mais evidentes que na face adaxial, 2 estípulas, aciculadas, inflorescência em racemo estrobiliforme, flores pistiladas várias, densamente agrupadas na base da inflorescência, frutos com denso indumento velutino, pétalas das flores estaminadas com denso indumento de tricomas vilosos internamente e os estames com tricomas vilosos na base.

Por ser um arbusto monóico, com folhas alternas, palmatinérveas, margem denteada, base glandulosa (com 1 par de glândulas), estípulas inteiras, inflorescência sem címulas bissexuadas na base, flores estaminadas com 11 estames, flores pistiladas com pétalas reduzidas, sépalas desiguais e estiletes bífidos, C. strobiliformis parece enquadrar-se em Croton sect. Geiseleria (Klotzsch) Baill., segundo a classificação de Webster (1993).

Agradecimentos - Ao CNPq, pelo auxílio concedido para estudo das Euphorbiaceae da Amazônia (Proc. no. 301.252/ 86-6); ao Dr. William Rodrigues, da UFPR., pela elaboração do texto em latim; ao desenhista Carlos A. Alvarez, pela confecção da ilustração; ao Dr. Paul E. Berry, da University of Michigan, pelas imagens cedidas, o que permitiu melhor

Figure 1. Croton strobiliformis Secco. A. Habit. A1. Detail of leaf margin with stipitate glands. B. Pair of stipules and gland. C. Pair of glands from leaf base. D. Detail of base of the inflorescence. E. Pistillate flower. F. Ovary. G. Calyx of pistillate flower; obsolete petals at the base. H. Fruit. I. Androiceum (from a bud in pre-anthesis) and separate stamen, in detail. J. Sepal, external side (from a staminate bud in pre-anthesis). L. Petals, external and internal sides (from a staminate bud in pre-anthesis). (From Lisboa et al. 1286). 
interpretação da espécie; ao Drs. L. Gautier e Alain Chautems, do Conservatoire et Jardin Botaniques, Genève, pela cessão de fotos de tipos; ao bolsista doutorando Alessandro Rosário, pela confecção da imagem digitalizada, e aos assessores pelas sugestões ao manuscrito.

\section{Referências bibliográficas}

CORDEIRO, I. 1992. Flora da Serra do Cipó, Minas Gerais: Euphorbiaceae. Boletim de Botânica da Universidade de São Paulo 13:169-217.

GOVAERTS, R., FRODIN, D.G. \& RADCLIFFE-SMITH, A. 2000. World Checklist of Euphorbiaceae (and Pandaceae). Vol. 2. Euphorbiaceae: Croton to Excoecariopsis. Royal Botanic Gardens, Kew.

MUELLER, J. 1873. Euphorbiaceae: Croton. In: C.F.P. Martius \& A.G. Eichler (editors), Flora Brasiliensis 11(2):82-273.
MURILLO-A., J. 1999. Composición y distribución del género Croton in Colombia, com cuatro especies nuevas. Caldasia 21:141-166.

SECCO, R.S. 1992. Notas sobre as lianas do gênero Croton L. (Euphorbiaceae). Boletim do Museu Paraense Emilio Goeldi, série Botânica 8:265-281.

WEBSTER, G.L. 1993. A provisional synopsis of the sections of the genus Croton (Euphorbiaceae). Taxon 42:793-823.

WEBSTER, G.L. 1994. Synopsis of the genera and suprageneric taxa of Euphorbiaceae. Annals of Missouri Botanical Garden 81:33-144.

WEBSTER, G.L., BERRY, P.E., AMBRUSTER, W.S., ESSER, H.-J., GILLESPIE, L.J., HAYDEN, W.J., LEVIN, G.A., SECCO, R.S. \& HEALD, S.V. 1999. Euphorbiaceae. In: P.E. Berry, K. Yatskievych \& B.K. Holst (editors), Flora of the Venezuelan Guayana 5:72-228. Missouri Botanical Garden Press, St. Louis. 